\title{
MULHER E EXECUÇÃO DA PENA: INSTRUMENTO DE EXCLUSÃO SOCIAL E CONSTRUÇÃO DE UMA CIDADANIA DE SEGUNDA CLASSE
}

Josep Pont VIDAL

Graduado em Sociologia - Universitat Bielefeld - Alemanha (1986), Mestrado em Sociologia Politica - Universitat Bielefeld (1987), Doutorado em Sociologia Política na Universidad de Barcelona (1997). Professor adjunto e pesquisador do Núcleo de Altos Amazônicos (UFPA). Atualmente realizando pos doutorado Universidade de Barcelona (UB). Link: http://lattes.cnpq.br/5665902360700834

Daiane Lima dos Santos

Doutoranda da Universidade de Alicante (Espanha); Mestra em Desenvolvimento Sustentável (NAEA/UFPA); especialista em Direito Administrativo e Administração Pública (UNAMA), Direitos Humanos (UCB) e Metodologia do Ensino Superior (UEPA). Defensora Pública do Estado do Pará (2007 à atualidade) e professora universitária desde 2006. Endereço para acessar este CV: http://lattes.cnpq. br/9577053859981662

\section{Resumo}

Discute a utilização do direito penal como forma de exclusão social, um instrumento de poder utilizado para aplicar penas privativas de liberdade a condutas de um determinado seguimento social. Analisa o encarceramento como mecanismo de exclusão social e limitador do exercício de direitos que afeta de forma diferenciada homens e mulheres. Discorre sobre a mulher encarcerada como integrante de um grupo vulnerável e questóes relativas ao gênero. Segue tratando do binômio recorrente: vulnerabilidade econômica e a seletividade do sistema penal. Apresenta o desenvolvimento da agenda política e a proteção da mulher em diplomas internacionais, e discute o encarceramento como forma de exclusão social. Apresenta um perfil das presas no estado do Pará representativo do cenário nacional. E, por fim propóe caminhos a serem trilhados para o enfrentamento da exclusão social da mulher encarcerada.

\section{Palavras-chave}

Mulheres encarceradas; Grupo vulnerável; Direito Penal; Exclusão. 


\section{Resumen}

Discute el uso del derecho penal como una forma de exclusión social, como una herramienta de poder utilizada para aplicar penas privativas de libertad a un seguimiento social. Examina el encarcelamiento como mecanismo de exclusión social y limitador del ejercicio de derechos que afecta a hombres y mujeres de forma diferente. Comprende a las mujeres encarceladas, como parte de un grupo vulnerable y las cuestiones relacionadas con el género. Habla del binomio recurrente: la vulnerabilidad económica y la selectividad del sistema penal. Se presenta el desarrollo de la agenda política y la protección de las mujeres en los diplomas internacionales, y discute el encarcelamiento como una forma de exclusión social. Presenta un perfil de presas en el estado de Pará representante en la escena nacional. Y, por último propone maneras de combatir la exclusión social de las mujeres encarceladas.

\section{Palabras clave}

Mujeres encarceladas; Grupo vulnerable; Derecho penal; Exclusión.

\section{Introdução}

As mulheres representam uma menor escala dentro do sistema punitivo, ou seja, 7\% dos encarcerados no Brasil, e no mundo as cifras são ainda menores. Todavia, quando o Direito penal as alcança, há uma ampliação de vulnerabilidade mais nefasta do que para os homens, pois é quebrado o papel social de submissão destinada à mulher em um sistema patriarcal.

Ademais, o cárcere feminino potencializa os danos sociais, principalmente em lares em que a mulher é a única ou principal provedora. Portanto, o estudo do binômio criminalidade/gênero permite um olhar os efeitos produzidos quando o sujeito criminalizado trata-se de uma mulher.

No Brasil em dezembro de 2011, conforme dados do INFOPEN (Sistema Nacional de Informações Penitenciárias), são 33.289 mulheres encarceradas. Todavia, encarceramento é crescente ${ }^{1}$, sendo o crescimento nacional, no período de 2005 a 2011, de 74\% no regime fechado. Em termos nacionais, o aumento do encarceramento feminino náo foi acompanhado pelo correspondente aumento do número de vagas, existindo 82 (oitenta e dois) estabelecimentos prisionais com capacidade para 20.231 mulheres, gerando um déficit de 13.827 em dezembro de 2011.

1 O Departamento Penitenciário Nacional, em decorrência da crescente taxa de encarceramento feminino, iniciou, em 2011, o Projeto Efetivação dos Direitos das Mulheres no Sistema Penal que, por meio da análise de dados do INFOPEN, lançou o Mulheres presas-dados gerais, publicado no site: www.mj.gov. br/depen. E visa ainda efetivar o INFOPEN mulher, com nova base de dados. 
Não obstante tais números a presa continua sendo em grande medida invisível quando se trata de politicas públicas de gênero, ou de lutas sócias das mulheres, ou ainda, quando se trabalha a proteção de grupos vulneráveis e de seus direitos. A mulher e o homem são tratados de forma indistinta no sistema penal, ocultando a desigualdade.

Nos primeiros tópicos o artigo trata da problematização, justificativas e objetivos, depois discorre sobre a mulher encarcerada como integrante de um grupo vulnerável e questôes relativas ao gênero. Segue tratando do binômio recorrente: vulnerabilidade econômica e a seletividade demonstrando a importância da renda para o estudo da criminalidade.

No tópico seguinte situa o leitor sobre a o desenvolvimento da agenda política e a proteção da mulher em diplomas internacionais, sem a pretensão de ser completo. E por fim trata do encarceramento como forma de exclusão social.

Apresenta do ultimo tópico dados sistematizados em pesquisa de campo realizada para elaboração de dissertação de mestrado no NAEA/UFPA, que utilizou técnica qualitativa e quantitativa aplicando questionários a 202 mulheres presas no Pará, que traz um perfil representativo do cenário nacional. E finaliza abordando a problemática em linhas gerais e propondo alguns caminhos a serem trilhados.

\section{Problematização}

$\mathrm{O}$ artigo propóe a discussão do encarceramento como um fenômeno seletivo, que apresenta relação com aspecto econômico e que produz um exercício de cidadania e de direitos diferenciadas para a clientela do direito penal. Propóe um olhar critico sob um matiz de gênero buscando elucidar: Como e se o encarceramento da mulher interfere na exclusão social e no exercício de direitos?

A investigação centrasse nesse problema, todavia acaba em alguma medida por tangenciar alguns outros como: quais as consequências do encarceramento feminino para o exercício de direitos? A cidadania exercida pelas mulheres presas é plena? O encarceramento da mulher é mais gravosas que o encarceramento dos homens? Existem estudos nessa área? Como a seletividade penal tem aborda essa temática? A mulher tem sido objeto de estudo da criminologia? O preso ou a presa exercer efetivamente sua cidadania?

Essas são algumas questôes planteadas no artigo objeto de reflexão, que na verdade são impossíveis de ser respondida na sua integralidade dada a limitação da proposta apresentada. No que nos centramos em busca aclaraçóes e suscitar o debate.

\section{Justificativa}

O direito criminal é seletivo e cumpre uma função de controle social. Estando em pleno desenvolvimento uma construção teórica crítica que busca correlação com a 
sociologia, filosofia e antropologia. Apresentando uma evolução da escola clássica, das teorias positivistas, teorias ecológicas, teoria da associação diferenciada, anomia e subcultura delitiva até chegar ao estagio atual de desenvolvimento.

Não obstante tal evolução o direito penal e o criminal sempre foram pensados para um sujeito masculino, elaborado a partir de um ideário do homem, estando à história das mulheres e o crime invisibilizado. Os manuais e mesmo as obras clássicas fazem pouca ou nenhuma referencia a mulher, que na verdade sempre sofreu as consequências repressoras do Estado.

Por outro lado, o movimento feminista busca a proteção das mulheres e quando se aproxima do direito penal o faz para descriminalizaçáo de tipos específicos como o aborto e adultério ou a busca de maior proteção aos bens jurídicos ligados à dignidade sexual. Não se aproximando das implicaçôes do delito de tráfico de entorpecentes que é hoje o crime mais importante em analise quantitativa, posto que mais da metade das mulheres brasileiras cumprem pena em regime fechado por esse delito.

No que temos no Brasil um verdadeiro espaço em branco desta historia, o cárcere de mulheres não ingressou na agenda teórica global ou brasileira, a presença de mulheres no cárcere recebe o mesmo tratamento da presença masculina, com exceção do direito a maternidade.

A mulher presa é um ser quase invisível teoricamente, socialmente e na elaboração e desenvolvimento de politicas públicas. Todavia, no Brasil representa $7 \%$ da populaçáo carcerária no que a questão de gênero deve integrar a pauta teórica e politica na discussão de direitos humanos.

\section{Objetivos}

Nesse sentido o artigo objetiva suscitar a discussão sob uma perspectiva de gênero, considerando a mulher encarcerada como integrante de um grupo vulnerável. E se propóe: Analisar o encarceramento como mecanismo de exclusão social e limitador do exercício de direitos que afeta de forma diferenciada homens e mulheres. E como objetivos específicos: Visibilizar a mulher encarcerada como integrante de um grupo vulnerável; Pontuar a proteção da mulher no ordenamento jurídico internacional; e, assinalar o encarceramento como mecanismo de exclusão social e limitador do exercício da cidadania;

\section{A Mulher Encarcerada como Grupo Vulnerável e a Questão de Gênero}

Etimologicamente a palavra vulnerabilidade vem do latim vulnerare, significando ferir, ou vulnerabilis, que causa lesão. Assim, vulnerável seria o que pode ser ferido, sujeito 
a ser atacado, derrotado, prejudicado ou ofendido. Historicamente, os vulneráveis vêm sendo considerados os deficientes mentais, físicos, as crianças, os senis e os institucionalizados, deixando-se de fora as populaçóes subdesenvolvidas, que padecem de vulnerabilidade social, como produto da repressão e da pobreza (BARCHIFONTAINE, 2006).

Para Guimarães (1996, p. 371), "grupos vulneráveis são aqueles grupos de pessoas que mais facilmente têm seus direitos humanos violados". A concepção de direitos humanos adotada pelas Organizações das Nações Unidas (ONU) é bem ampla, englobando desde uma prisão arbitrária até a ausência de condiçóes de vida adequada, incluindo-se normalmente nestes grupos, além dos citados alhures, populações indígenas, os doentes terminais, os trabalhadores migrantes, os refugiados, as minorias nacionais ou étnicas, religiosas e linguísticas, e as vítimas da pobreza extrema e crônica.

A ampliação dos grupos vulneráveis é feita diuturnamente. Claramente são reconhecidos como tal o idoso, a criança, a pessoa com deficiência e os homossexuais. Todavia, a este rol devem ser acrescidos o preso, a presa e os egressos do sistema penitenciário, posto que também sofrem, potencialmente, a violação de seus direitos.

Na medida em que a privaçáo de direitos transforma os presos em uma minoria desprotegida, a sociedade tem a falsa noção de que o abuso sobre os presos não merece a atenção pública e que a prisão quanto mais tenebrosa mais eficiente (SÉGUIN, 2001, p. 39).

Desenvolve-se o processo de desvalorização dos direitos fundamentais descritos por Beiras (1997, p. 21), ou seja, que "los derechos fundamentales de las personas que se hallan privadas de su liberdad se encontran 'devaluados' respecto de los derechos semejantes de aquellos indivíduos que se desenvuelven em la vida em liberdad" . Em outras palavras, que os direitos dos reclusos são de segunda categoria. Constando o desenvolvimento de um discurso jurídico da desvalorização desses direitos, que nega a satisfação das mínimas necessidades do recluso. A aplicação da pena apresenta como consequência o afloramento de outra dimensão de direitos, que esta em um plano inferior, permitindo assim que matem o preso se este pretende escapar, que se exija trabalho mesmo que não paguem um salário digno, que é possível abrir e censurar sua correspondência. Relegando os outros direitos do preso a um segundo plano quando comparado a uma pessoa que goza de liberdade.

Boaventura de Souza Santos (2003) ao desenvolver os mecanismos do sistema capitalista relativo à igualdade e exclusão afirma que a cidadania, que é soma dos direitos efetivamente exércitos pelos indivíduos ou grupos, nas sociedades capitalistas resume-se a uma questão de graus. Existindo três categoriais: os super-cidadãos, os restantes e os não-cidadãos.

Existem os super-cidadãos - os que pertencem à sociedade civil ínti$\mathrm{ma}-\mathrm{e}$ os restantes. Os restantes, que formam a sociedade civil estranha, 
albergam cambiantes múltiplos de cidadania. E existem ainda os nãocidadãos, indivíduos e grupos sociais que pertencem à sociedade civil incivil e às zonas fronteiriças entre a sociedade estranha e a sociedade civil incivil. As experiências de vida dos indivíduos pertencentes à segunda categoria correspondem a esta ausência de cidadania e caracterizam realmente não só as suas relaçóes com o Estado, como ainda as suas interacçóes com os outros indivíduos, incluindo por vezes os que compartilham a sociedade civil incivil. Estas experiências de vida variam de acordo com a circunstância de o não-cidadão haver sido expulso de algum tipo de contrato social e, consequentemente, da inclusáo social que este tornava possível (pós-contratualismo), ou de o cidadão não haver alguma vez sequer experimentado qualquer tipo de inclusão social contratual (pré-contratualismo). No primeiro caso, a cidadania é vivida como ruína ou memória, enquanto, no segundo, ela é ou uma aspiração irrealista ou uma ideia absolutamente ininteligível. A não-cidadania é o grau zero da inclusão assente no contrato social. (SANTOS, 2003, p.22)

O exercício efetivo de direitos que constitui o grau de cidadania depende da inclusão ou exclusão social, sendo a prisáo, os manicômios, as instituiçóes totais o lugar por excelência da exclusáo social, que alberga os já excluídos socialmente, e, por conseguinte limitando seu grau de cidadania.

A prisão como instituição total gera estigmas, constituindo-se em um rito de passagem que diminui as chances do reingresso no mercado de trabalho, relegando-os ao trabalho informal, tendo em vista a corriqueira exigência dos antecedentes criminais para a contratação. Ademais, a deficiência deste grupo ao acesso à educação é outro fator limitante, que também não é suprido quando da permanência na prisão.

A mulher é tida como um grupo vulnerável, considerando-se tanto a distinção de sexo, como natural e biológica, e a de gênero, como social e cultural. Daí a necessidade da declaração da igualdade entre homem e mulher nos mais diversos diplomas legislativos ao longo da história.

Portanto, a utilização do termo "gênero" em uma dimensão analítica necessita de novos paradigmas teóricos, de um olhar histórico nas diferenças construídas socialmente entre os sexos, bem como das relaçóes de poder que permeiam tal construção na interação humana, saber como funcionam e como se transformam as relaçôes entre homens e mulheres.

Para Conceição (2009), o feminismo aparece como um pensar que promove mudanças, que desconfia da naturalidade, que se autocritica, sendo capaz de criticar até o binário sexo-gênero, quebrando as identidades rígidas, buscando um mundo em que ser homem ou mulher não faça diferença, não faça pensar em qualquer vantagem. 
A "mudança do sentido da palavra mulher tem se dado de forma lenta e se dá sempre por meio de relaçóes de poder, da desigualdade dos poderes, de suas lutas" (AZERÊDO, 2011, p. 30).

Enquanto esta construção histórica não ocorre e a igualdade material não é alcançada em sua plenitude, a questão de gênero continua a ser relevante. $\mathrm{Na}$ medida em que estamos longe deste ideário de igualdade, seja relacionado à constituição de um papel social para a mulher, que é um locus vulnerável em uma sociedade patriarcal, seja quando comparamos gênero e relaçóes de produção.

A relação entre homens e mulheres estabelece-se social e culturalmente sobre o exercício político de divisão ou compartilhamento de poder. Assim, a violência de gênero não seria apenas aquelas impostas pelos homens às mulheres no âmbito de suas relaçóes interpessoais. Teria um aspecto mais amplo. Seria toda espécie de ação voltada a reduzir as possibilidades de participação feminina nos espaços de decisão, o que ocorre não apenas no âmbito doméstico, mas, sobretudo no espaço público (PADRO; XIMENES, 2012).

A prática estatal que ignora os recortes sociológicos de gênero na valoração das condutas penais de mulheres é não apenas recorrente no judiciário brasileiro, mas representa a seletividade sexista, racial e de classe sobre a qual se sustenta a dominação elitista masculina e branca da sociedade brasileira, negando intencionalmente a um número cada vez maior de mulheres, a sua condição de sujeitos de direitos (PADRO; XIMENES, 2012, p. 110).

É mister para redução da vulnerabilidade, que além da realização de direitos sociais da apenada, seja reduzida sua invisibilidade com a presença feminina nos espaços sociais na condição de sujeito.

Outro aspecto que precisar ser analisado e que amplia a vulnerabilidade refere-se à cultura legítima. Tal cultura é massificada nos meios de "comunicação de massa", que criam um cenário binário em que existe o mocinho e o bandido, o cidadão e o criminoso, o bom e o mau, legitimando uma visão social em que o preso é o outro. Um estado em que a violência precisa ser combatida, sendo a mídia um importante veículo a desempenhar a legitimação de um discurso em que a visão social da presa, isto é, sua voz não é ouvida, produzindo e reproduzindo a violência simbólica. A imprensa condena o fato e a pessoa do preso.

Os novos papéis que a mídia entrou a desempenhar, configurando-se como um conjunto de agências de comunicaçáo social do sistema penal que podem mesmo desempenhar tarefas próprias das agências executivas, resultam não apenas numa estável legitimação publicitária da hipercriminalização, mas sobretudo num instrumento de compreensão induzida dos conflitos sociais a partir da estreita lógica binária infracional. Este 
novo sistema penal, na sua face dura, não postula no encarceramento as utopias preventivas ressocializantes, senão a mais e asséptica neutralização do condenado (BATISTA;ZAFFARONI, 2003, p. 487).

A construção da dominação vai além do econômico, para a construção de habitus ou subjetivaçôes de subordinação, em que a mulher não se apresenta como sujeito de sua própria história, como nos contos da Branca de Neve e da Cinderela, desde cedo internalizadas, que ficam aguardando a chegada do príncipe encantado que irá salvá-las.

A mulher encarcerada tem a realização desse sonho ainda mitigada, pois além da questão de cor e gênero, ainda padece de mais um estigma: o cárcere, que lhe marcará em todas as relaçóes sociais desenvolvidas.

Assim, ocupa muitas vezes o lugar de não sujeito, convivendo com a dicotomia entre santa/puta, figurando como vítima de violência, o que ensejou a criação, no Brasil, da Lei Maria da Penha, mas pouco diz sobre a possibilidade da vulnerabilidade econômica, social, racial e de gênero apresentar outra resposta, no caso à prática de crime. Tal ausência gera a invisibilidade da mulher como sujeito de delitos, até porque em termos quantitativos não é a mulher a grande preocupação do sistema penitenciário.

A simples proposta feminista de igualdade com os homens não é a solução dos problemas, pois que na realidade é a sociedade maculada pela desigualdade, que simula a igualdade. Assim, a diferença não é apenas sexual, é de raça, é de classe, está implícita na posição social da mulher encarcerada, que não atendeu aos padróes exigidos, sendo culpada por sua desigualdade ${ }^{2}$.

\section{Um Binômio Recorrente: Vulnerabilidade Econômica e a Seletividade Penal}

Em relação à mulher encarcerada, considera-se necessário um diálogo com Wacquant (2007) que descreve de forma mais específica o processo de criminalização da pobreza, em que as políticas sociais foram substituídas pelo cárcere, a partir de um estudo realizado nos Estados Unidos.

Wacquant (2007) faz uma análise acerca da reforma de assistência social dos Estados Unidos com a implementação da Personal Responsabilit yend Work Opportunity Reconciliation, de 1996, uma reforma de perspectiva neoliberal que póe fim ao Welfare, instalando-se o Workfare, implementando cortes nos benefícios sociais, com o discurso de que estimulava uma "cultura de dependência".

2 Muito se escreveu a cerca da mulher, a história da sexualidade, as diferenças entre sexos, gêneros e a formação da identidade; para tal, ver Foucault (A História da Sexualidade e a Vontade do Saber), Freud, Beauvoir, e dentre obras recentes, Luci Helena Baraldo Mansur (Solidão e solitude: Passagem feminista do Estado civil ao território da alma). 
Ele descreve a passagem de políticas públicas relacionadas à diminuição da pobreza para a criminalização da pobreza, de um Estado Social para o penal, sem qualquer preocupação de inserção da populaçáo, majoritariamente negra e migrante, com a consecução de emprego como a formação profissional ou a criação de postos de trabalho.

Em relação à mulher, os governos estaduais receberam incentivos para reduzir as cotas de atendidas pela assistência social, e tais planos seriam inteiramente voltados para o aperfeiçoamento das mães solteiras carentes por intermédio de oficinas de habilitação voltadas para ensiná-las as normas culturais dominantes e a submissão no trabalho. Tratando a pobreza como medo de falhar, dependência, má atitude, mentalidade de vítima e baixa autoestima. E, por fim os beneficiários da assistência foram tratados como desviantes, diminuindo-se os benefícios e ampliando-se os critérios para ingresso e permanência nos programas visando à diminuição de gastos.

Tais gastos foram diminuídos e houve a passagem do welferestates para o workfarestates, sendo paralelamente ampliado o braço carcerário do Estado. Pearce (1978), apud Carlás e Smircich (1999), também assevera a ocorrência da "feminização da pobreza" havendo uma tendência de concentração de casos de baixa renda familiar, estando à mulher desempregada e dependendo de assistência social.

No Brasil, a política do welferestates não foi implantada em sua plenitude, como ocorreu nos EUA. Portanto, políticas visando o Estado de bem estar social somente podem ser diminuídas com o neoliberalismo, posto que a desigualdade social no Brasil é latente, ocupando a $84^{a}$ posição entre os 187 países avaliados no estudo, apesar de ter subido uma posição no ranking 2011 do IDH medido pelo PNUD, ocupando a 6 colocação nas economias do mundo. Portando, o processo ocorrido nos Estado Unidos tomou outras feiçôes no Brasil, em face das diferenças do processo de colonizaçáo e desenvolvimento.

Nesse sentido, no Brasil importou-se a política penal de endurecimento de penas, no que podemos citar a Lei de Entorpecentes (Lei n. 11.343 de 23 de agosto de 2006) que ampliou as penas cominadas aos delitos nela previsto, não havendo tal endurecimento do aparelho penal relativo a crimes cometidos pelas classes abastardas. De modo que, o fenômeno do endurecimento penal de crimes geralmente praticados pelas classes populares foi ampliado (GOMES, 2007), como ocorreu nos EUA.

Todavia, no âmbito do encarceramento feminino temos as presas provisórias e definitivas em sua maioria acusadas ou condenadas pela prática de tráfico de drogas, não havendo o desenvolvimento de políticas públicas efetivas visando à mudança deste perfil. Assim como nos EUA, no Brasil não são desenvolvidas políticas de geração de emprego e renda eficientes para essa parcela da populaçáo. 
A afirmação de Wacquant (2007) representa bem a realidade brasileira, pois na mesma década em que se veem os pequenos traficantes e consumidores de drogas dos bairros pobres serem jogados na prisão aos milhares, é também aquela em que a "malversação em quadrilha organizada", crime típico do capitalismo dominante, se generaliza, estando os "ricos" em uma mansidáo penal. Para ele a instituição carcerária serve como principal instrumento de gestão da miséria na América.

Prossegue a análise, inferindo que depois de presos, os orçamentos reservados às atividades voltadas à reinserção foram os primeiros a ser cortados, embora não tenham atingindo sequer um décimo das despesas carcerárias (WACQUANT, 2007, p. 295). A filosofia penal hoje dominante nos Estados Unidos pode ser resumida nesta expressão, muito em voga entre os profissionais penitenciários: "Mike prisoners smell like prisiones" - fazer com que os presos cheirem a presos. O encarceramento, diz ele, deve voltar urgentemente a ser o que era em sua origem e que nunca deveria ter deixado de ser: um sofrimento (a palavra prisão deriva de poena, que significa dor) (WACQUANT, 2007, p. 296).

Desta feita, o autor, a partir de uma análise macro, indica a função da prisão, sustentando a tese de que possui importância fundamental na manutenção do neoliberalismo, pois apresenta uma ameaça de punição e controle dos excessos e desvios, assim adequando os indivíduos a um modelo de trabalho precário de desregulamentaçáo. Logo, as "prisôes da miséria" produzem subjetividades punitivas, realimentando a necessidade das prisóes, identificando na pobreza, indivíduos perigosos potencialmente criminosos que necessitam de controle (WACQUANT, 2007; COIMBRA, 2001; GUIMARAES; MENEGHEL; OLIVEIRA, 2006).

\section{0 Desenvolvimento da Agenda Política e a Proteção da Mulher em Diplo- mas Internacionais}

A discussão da mulher enquanto grupo vulnerável ganha relevo em várias agendas e compromissos internacionais sobre a proteçáo dos direitos humanos e do desenvolvimento, tal qual na Agenda 21, adotada pela Conferência das Naçóes Unidas sobre Meio Ambiente e Desenvolvimento, realizada no Rio de Janeiro, em junho de 1992.

A proteção aos grupos vulneráveis objetiva: garantir que todos os indivíduos que deles fazem parte tenham oportunidade de desenvolver plenamente seus potenciais (inclusive um desenvolvimento saudável físico, mental e espiritual); dar aos jovens a oportunidade de desenvolver, estabelecer e manter vidas saudáveis; permitir que as mulheres desempenhem seu papel chave na sociedade; e, por fim, apoiar populaçóes indígenas por meio de oportunidades educacionais, econômicas e técnicas.

Enquanto a Agenda Brasileira, buscando a redução das desigualdades sociais, traz como estratégia ${ }^{3}$, relativa à promoção de grupos socialmente vulneráveis, as seguintes 
açóes: articular uma rede envolvendo órgãos governamentais, organizaçóes do terceiro setor e instituiçóes privadas voltadas para o resgate de experiências variadas de capacitação para a cidadania e para a sustentabilidade; garantir o exercício dos direitos sexuais e reprodutivos das mulheres por meio de açóes integradas no âmbito do governo e da sociedade civil. (PUCSP, 2013, não paginado).

Outros documentos internacionais importante são os produzidos pelo Programa das Naçôes Unidas para o Desenvolvimento (PNUD) chamado de Relatório de Desenvolvimento Humano (RDH), que cria, em 2011, o Índice de Desigualdade de Gênero (IDG), que analisa três dimensões: saúde reprodutiva, capacitação e mercado de trabalho. Tal índice varia de zero a um, e quanto mais alto seu valor, maior a desigualdade entre mulheres e homens. Em uma lista de 146 países, o Brasil ficou na 80ª posição.

Não se pode olvidar que é longa a discussão acerca dos direitos das mulheres e a construção de documentos internacionais ${ }^{3}$ visando à igualdade de gênero. Dentre elas a Convenção Interamericana para Prevenir, Punir e Erradicar a Violência Contra a Mulher - Convenção de Belém do Pará, que define o conceito de violência contra a mulher como

[...] qualquer ato ou conduta baseada nas diferenças de gênero que cause morte, dano ou sofrimento físico, sexual ou psicológico à mulher, tanto na esfera pública quanto na esfera privada. Aponta, ainda, direitos a serem respeitados e garantidos, deveres dos Estados participantes e define os mecanismos interamericanos de proteção. (Promulgada por meio do decreto $\mathrm{n}^{\circ} 1973$, em $1^{\circ}$ de agosto de 1996.);

Há de se destacar ainda que dos oito objetivos do milênio estabelecidos pela ONU, em 2000, para serem atingindo em 2015, após analisar os principais problemas do mundo, vários estão relacionados às mulheres. $\mathrm{O}$ terceiro é a igualdade entre os sexos e a autonomia das mulheres, posto que no Brasil, as mulheres já estudam mais que os homens, mas ainda têm menos chances de emprego, recebem menos do que homens trabalhando nas mesmas funções e ocupam os piores postos. Em 2008, 57,6\% das brasileiras eram consideradas economicamente ativas, frente a 80,5\% dos homens. Em 2010, elas ficaram com 13,6\% dos assentos no Senado, 8,7\% na Câmara dos Deputados e 11,6\% no total das Assembleias Legislativas (PNUD, 2013, não paginado).

3 Carta das Nações Unidas (1945); Declaração Universal dos Direitos Humanos (1948); Convenção Interamericana Sobre a Concessão dos Direitos Civis à Mulher (1948); Convenção sobre os Direitos Políticos da Mulher (1953); I Conferência Mundial sobre a Mulher (Cidade do México, 1975); Convenção Para Eliminar Todas as Formas de Discriminação Contra a Mulher - CEDAW (1979); II Conferência Mundial sobre a Mulher (COPENHAGUE, 1980). O Instituto Internacional de Pesquisa e Treinamento para a Promoção da Mulher (INSTRAW) é convertido em um organismo autônomo no sistema das Naçōes Unidas; III Conferência Mundial Sobre a Mulher (NAIRÓBI, 1985); Convenção Interamericana para Prevenir, Punir e Erradicar a Violência Contra a Mulher (BELÉM, 1994); IV Conferência Mundial sobre a Mulher (BEIJING, 95). 
O grande rol de normas internacionais que passaram a integrar o direito brasileiro por meio da ratificação e posterior promulgação, bem como a modificação constitucional do art. $5^{\circ}, \$ 3^{\mathrm{a}}$ acrescido pela Emenda 45, de 08/12/2004, tornam-se equivalentes a emendas constitucionais os tratados e convençóes internacionais sobre direitos humanos que forem aprovados em cada casa do Congresso Nacional, em dois turnos, por três quintos dos votos dos respectivos membros. A previsão do art. $5^{\circ}, \S 4^{\mathrm{a}}$, em que o Brasil se submete à jurisdiçáo do Tribunal Penal Internacional, e tem manifestado adesão, demonstram a ampliação do rol de direitos humanos, que podem inclusive agora galgarem status constitucional.

Não obstante, tal ampliação à realização de tais direitos, o fornecimento de condiçóes para o desenvolvimento humano ainda precisa avançar, o que pode ser constatado facilmente saindo-se do âmbito estritamente jurídico e passando-se a analisar indicadores econômicos. Em relação ao IDH, o Brasil ocupa somente a $84^{\text {a }}$ posição e o IDG, ocupa a $80^{a}$ posição.

Em relação ao conceito de "Grupos Vulneráveis", podemos dizer que "são aqueles grupos de pessoas que mais facilmente têm seus direitos humanos violados" (GUIMARÁES, 1996, p. 371) e o adotado pelo PNUD para desenvolvimento humano "definido como um processo de ampliação das escolhas das pessoas para que elas tenham capacidades e oportunidades para serem aquilo que desejam ser [...] o foco é transferido do crescimento econômico, ou da renda, para o ser humano" (PNUD, 2013, não paginado).

Chega-se assim a três conclusóes: 1 - não é a extensão da carta de direitos existentes em um país que elimina sua violação e os torna exequíveis; 2 - o desenvolvimento econômico de um país por si não elimina a existência de grupos vulneráveis; 3 - a atenção deve estar voltada para o ser humano, observando características sociais, culturais e econômicas.

\section{O Encarceramento como Forma de Exclusão Social}

A ideia do encarceramento como forma de exclusão social necessariamente amplia o foco para discutir como a politica criminal é dirigida e qual a motivação da punição de determinadas condutas, enquanto outras que apresentam igual ou maior dano social são esquecidas, ficando à margem do aparelho punitivo. Isto é, "por que os crimes contra os consumidores não são punidos?”, "por que é possível realizar transação penal em crimes ambientais?", "por que os crimes de colarinho branco não são alcançados pelo direito penal e os políticos criminosos ainda estão se reelegendo?”

Batista e Zaffaroni (2003) trazem a hipótese de que o sistema penal de cunho neoliberal, direcionado aos contingentes humanos, por ele mesmo marginalizado, opera 
mediante uma dualidade discursiva, dividindo-se em dois tipos de consumidores, quais sejam, os ativos e os falhos. Para o grupo de consumidores ativos, o sistema penal aplica medida despenalizante, em sentido amplo, tais quais as leis dos juizados especiais estaduais e federais e a previsão de substituição de penas privativas de liberdade por restritivas de direitos.

Ao segundo grupo, de consumidores falhos, corresponde a uma privação de liberdade neutralizadora, com uma política diametralmente oposta, tais como a lei dos crimes hediondos (Lei 8.072/90) e o regime disciplinar diferenciado. Deste modo, a programação criminalizante neoliberal apresenta dois caminhos conflitantes, com a convivência de dois subsistemas penais com regras e procedimentos para duas clientelas de extraçóes sociais igualmente distintas ${ }^{4}$.

A criminalização é direcionada à configuração e preservação de lugares sociais, cujas fronteiras delimitadas funcional e territorialmente não poderiam ser ultrapassadas. Assim, enquanto cumpria as intermináveis jornadas de trabalho, o operário estava em seu lugar, confortado pelo oportuno discurso ético-jurídico que associa trabalho à honestidade e ociosidade à corrupção (BATISTA; ZAFFARONI, 2003).

A população mais pobre constitui o grande contingente dos institucionalizados, criminogenizados, psiquiatrizados, considerada como ameaçadora, tendo a atribuiçáo social de objetos de legitimação dos discursos e lógica da necessidade de existência dos aparatos, das práticas e das instituiçóes de controle penal. A política deliberada de pseudocuidado é camuflada pelo discurso de tolerância zero à criminalidade (BRAUNSTEIN, 2007, p. 43). Deste modo, "o sistema penal se retroalimenta deliberadamente das desigualdades sociais, sobretudo daquelas relacionadas a gênero, raça e classe" (PRADO; XIMENES, 2012, p. 108).

Assim, somente os vulneráveis às práticas e aos aparatos de dominação, os consumidores falhos são clientela histórica do direito penal e das penas privativas de liberdade. A dicotomia ora apresentada sempre esteve presente entre cidadãos e não cidadãos, entre "selvagens" e cristãos, entre ricos e pobres, sendo historicamente renovada.

Atualmente, a lógica neoliberal é determinante para o aumento da vulnerabilidade social, pois banaliza a violência enquanto estrutura de dominaçáo, utiliza o direito penal como forma de controle social, revertido de um discurso legitimador de fortalecimento do estado penal e diminuição da violência: o discurso da "tolerância zero".

Portando, a prática do sistema penal está dirigida para castigar os pobres e não necessariamente para aqueles que trazem mais danos sociais. Durante a história nacional,

4 Tal ideia dicotômica e classificadora também foi apresentada por vários autores: nas categorias pessoa e não pessoa realizada por Goffman (2010); cidadão e não cidadão por Jakobs (2001); Zoé e bíos, homo sacere homo sapiens por Agabem (2010); cidadão e “subcidadão” por Souza (2006). 
o Direito penal foi utilizado como controle social de forma latente. Tal fato já fora destacado por Lemos-Capeller (1990), e desde 1981 a produçáo do grupo de criminologia de Maracaibo, que teve enorme importância para o pensamento criminológico latino-americano, concluía após vários estudos que a criminalidade que causa maior dano social na América latina é a decorrente da exploração econômica e do abuso do poder político. Todavia, na contramão dessa argumentação, a criminalidade efetivamente combatida era a relacionada à criminalidade social.

Garland (2008) observa o crime como uma construção política, e a resposta a ele, a punição, não está desarticulada das outras instituiçóes sociais, pois o crime seria uma construção política, um fenômeno que emerge das interaçóes sociais em um mundo construído a partir de relaçóes de poder já dadas e marcadas pela desigualdade de recursos de poder.

Segundo ele, a partir dos estudos das sociedades estadunidense e inglesa (associada à crise do Welfere State e a aplicação de uma política neoliberal), com repercussóes no tratamento duro empregado ao crime, foi abandonado o projeto de inclusáo, de ressocialização, passando a confiar em elementos de exclusão:

Uma sociedade precisa refletir não somente a respeito de como os indivíduos devem ser punidos, mas sim sobre questôes mais amplas, como a política penal afeta comunidades, opinióes políticas, economia e cultura da sociedade de maneira geral (GARLAND; COMCIENCIA, 2008).

Como define Zaffaroni (2002), existe uma seletividade da criminalização secundária com uma orientação burocrática sobre pessoas sem poder, relativa a fatos grosseiros e alguns insignificantes, provocando uma distribuição seletiva que toma a forma de epidemia, atingindo apenas aqueles que se tornam mais vulneráveis à criminalidade seletiva, na medida em que suas características se enquadram perfeitamente nos estereótipos criminais, visto que sua educação somente permite realizar açóes ilícitas, toscas e de fácil detecção, e por que o etiquetamento permite a assunção do estereótipo, cumprindo-se então a profecia. Assim, a criminalização da pobreza revela tal mecanismo, pela natureza dos atos praticados que em regra são delitos patrimoniais e de tóxicos e pelo perfil dos criminalizados.

Igualmente, a discussão sobre a criminalidade passa a transcender os motivos que conduzem as pessoas e as mulheres ao cárcere. Em outras palavras, temos que parar de perguntar sobre quais os motivos determinantes que levaram uma pessoa específica a cometer crimes. Isto é "por que a Maria se envolveu com drogas?", "ela precisava mesmo do dinheiro?”, "por que ela náo foi ser diarista, babá ou cozinheira?”. Temos que perguntar: "por que o delito de trafico de entorpecentes tem uma pena tão alta quanto comparado 
aos delitos de colarinho branco?", "por que o direito penal protege o matrimonio de forma mais dura que a vida?", "por que uma egressa e pior vista que um egresso?".

Na discussão apresentada, a mulher encarcerada pertenceria ao grupo de consumidores falhos, o que pode ser constatado por meio da análise do perfil da penada, mesmo que superficial, que possui pouco capital econômico, bem como, pela natureza dos crimes a elas imputados, em sua maioria tráfico de drogas, relacionados, portanto, à aquisiçáo de renda, que se enquadra na politica criminal de endurecimento da pena.

Isso nos levando a concluir que a mulher sofre uma dupla inclusão pelo direito penal: a primeira refere-se à sua condição econômica, enquanto a segunda refere-se à questão cultural (MANSUN, 2011), que pode ser abordada na perspectiva de neutralizar a cultural dos povos dominados, ou ainda, para a reafirmaçáo da cultura do patriarcado para manutenção dos papeis sociais.

Além da questão econômica, soma-se, conforme Sposato (2007, p. 254), o argumento de que "as mulheres criminalizadas enfrentam práticas jurídicas e institucionais profundamente marcadas por relaçóes patriarcais”, sofrendo assim, uma discriminação específica, pois o sistema penal tende a reproduzir a estrutura social e manter a estrutura de gênero.

Tal elemento cultural da criminalização feminina é histórico, pois na Idade Média e depois na colonização brasileira, estava ligada à bruxaria, à feitiçaria; enfim, à transmissão da cultura. Destarte, a criminalização de sua conduta mitiga a transferência às outras geraçóes, o que foi feito no Medievo com as feiticeiras e também no Brasil com as velhas índias das aldeias, selvagens, "mulheres de seios caídos", retratadas como distribuidora da carne humana (MANSUR, 2011, p. 63-72), sendo este, um dos caminhos possíveis para se romper a cultura dos povos dominados.

Para Prado; Ximenes (2012), a subordinação feminina é decorrente da forma como a mulher foi construída socialmente, possibilitando mostrar que os espaços sociais foram mudando, inclusive referente às práticas delituosas. Assim,

Enquanto permanecessem confinadas na zona que uma explicita geopolítica criminal lhes destina, as prostitutas estavam em seu lugar, amparadas por um curioso discurso ético-jurídico que lhes reconhece uma "utilidade social”; fora daí passavam a constituir um escândalo, que a impressa denunciaria e a polícia reprimiria severamente, ou uma ofensa à saúde pública (BATISTA; ZAFFARONI, 2003, p. 457).

Na década de 1970, a principal causa de encarceramento feminino estava ligada aos movimentos subversivos. Isto ocorreu no auge do regime militar, seguido em menor escala pelos tipos penais denominados como femininos, ou seja, o infanticídio, 
o homicídio "passional” e o aborto (PRADO; XIMENES, 2012). Hodiernamente, a incursão nas práticas delituosas está ligada ao tráfico de drogas.

Ora, a mudança nas categorias de crimes em que as mulheres são condenadas demonstra uma mudança no desempenho de seu papel social, visto que no Brasil colônia as condenaçóes estavam ligadas à bruxaria e ao curandeirismo; relacionada ao papel público de cuidado desempenhado pela mulher, passando aos crimes considerados femininos, como o infanticídio.

O homicídio passional demonstra seu papel privado. Durante o regime militar, novamente, o papel público é relevado com o envolvimento das mulheres em lutas políticas, e atualmente a criminalidade está ligada, novamente, ao papel público, a mulher como provedora da família, havendo correlação à prática de tipos penais para aferição de recursos financeiros.

O rigor do poder punitivo estatal relativo à mulher tem dois efeitos específicos: reforça a construção patriarcal de reserva de determinados espaços para participação exclusivamente masculina, razão por que são impostas penas mais severas para mulheres do que para homens por idêntica imputação criminosa. E, por fim, seleciona e exclui da possibilidade de ascensão social e econômica as que compóem o maior grupo social brasileiro: mulheres negras e pobres (PRADO; XIMENES, 2012).

Apesar de representar uma menor escala dentro do sistema punitivo, (as mulheres representam 7\% dos encarcerados), quando o Direito penal as alcança, há uma ampliação de vulnerabilidade mais nefasta do que para os homens, pois é quebrado o papel social de submissão destinada à mulher, o de mulher virginal. Ora porque são as mulheres que exercem a guarda da prole e dos idosos majoritariamente nos lares. Ora porque a ocupação anterior das mulheres que estão no cárcere relaciona-se a atividades domésticas exigindo mais confiança para recolocação no mercado de trabalho.

Exemplificando: no imaginário social é mais fácil compreender as razões que levam o homem a delinquir; ou ainda é mais fácil contratar um egresso como pedreiro, carpinteiro, capinador, ou qualquer outro serviço braçal, do que compreender a mulher presa e suas razóes, ou contratá-la como cozinheira ou babá para cuidar dos filhos e do lar de uma família. Ademais, quando o homem é encarcerado, a mulher assume a prole; mas isso não ocorre quando é a mulher a encarcerada.

Assim, o cárcere feminino potencializa os danos sociais, principalmente em lares em que a mulher é a única ou principal provedora. Portanto, o estudo do binômio criminalidade/gênero permite um olhar acerca dos efeitos produzidos quando o sujeito criminalizado trata-se de uma mulher. 
É fato que, em termos percentuais, as mulheres representavam, em dezembro de 2011, conforme dados do INFOPEN (Sistema Nacional de Informaçóes Penitenciárias), $7 \%$ do total da população penitenciária brasileira. Em termos absolutos, são 33.289 mulheres encarceradas. Tal encarceramento é crescente ${ }^{5}$, sendo o crescimento nacional, no período de 2005 a 2011, de 74\% no regime fechado. Esse dado significa um acréscimo de $159 \%$ de presas provisórias, conforme se vislumbra pelo gráfico abaixo. Em termos nacionais, o aumento do encarceramento feminino não foi acompanhado pelo correspondente aumento do número de vagas, existindo 82 (oitenta e dois) estabelecimentos prisionais com capacidade para 20.231 mulheres, gerando um déficit de 13.827 em dezembro de $2011 .^{6}$

\section{Gráfico 1 - Encarceramento feminino por regime}

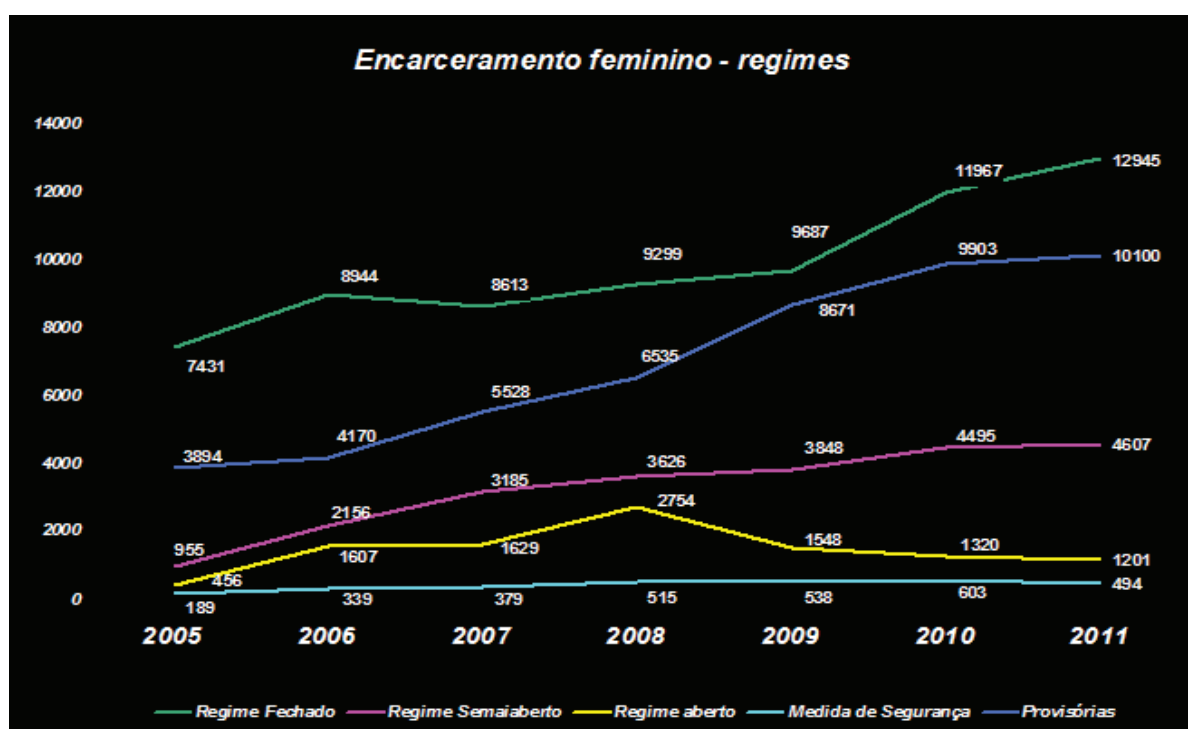

Fonte: Ministério da Justiça (2011)

A escolaridade da presa brasileira é outro fator que demonstra seu grau de exclusão, conforme dados abaixo.

5 O Departamento Penitenciário Nacional, em decorrência da crescente taxa de encarceramento feminino, iniciou, em 2011, o Projeto Efetivação dos Direitos das Mulheres no Sistema Penal que, por meio da análise de dados do INFOPEN, lançou o Mulheres presas-dados gerais, publicado no site: www.mj.gov. br/depen. E visa ainda efetivar o INFOPEN mulher, com nova base de dados.

6 Os dados coletados no INFOPEN, informados pelo Estado, representando o sistema oficial, devem ser analisados criticamente. 


\section{Gráfico 2 - Escolaridade das presas no Brasil}
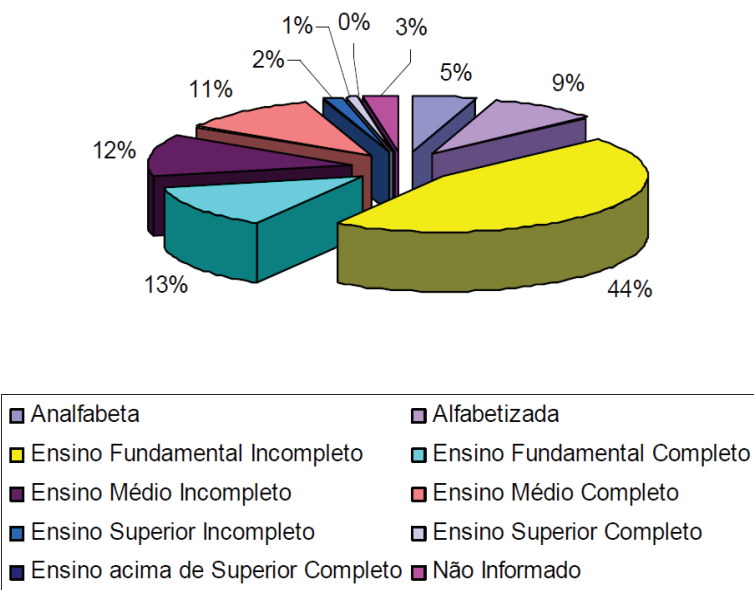

Fonte: Projeto Efetivação dos Direitos das Mulheres no Sistema Penal/MJ (2011).

A população carcerária feminina brasileira, em sua maioria, é de raça negra ou parda; de idade entre 18 a 29 anos; e de baixa escolaridade: analfabetas, alfabetizadas e com ensino fundamental incompleto.

\section{Mulher Presa: de Quem Estamos Falando?}

Apresenta se os principais dados do perfil da mulher presa no Pará, em pesquisa de campo realizada em 2012 nos três centros de recuperação que abrigavam mulheres no Pará localizados em Ananindeua, Santarém e Marabá, com aplicação de questionários para 202 mulheres que representavam 73\% do universo, sendo possível traçar o perfil

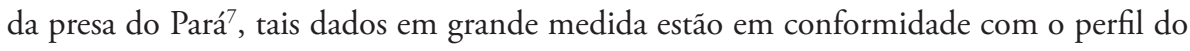
INFOPEN (Sistema Nacional de Informaçóes Penitenciarias), todavia são mais completos tendo em vista que os questionários continham 61 itens. Segue os principais dados sistematizados (SANTOS, 2013).

A pesquisa centralizou a atenção nas condições sociais, econômicas, culturais e de saúde da mulher encarcerada, e não apenas sobre o individuo, assim como fazem as abordagens sociológicas. Constatou-se que a prática do encarceramento é estrutural, e o perfil

7 A pesquisa é qualitativo e quantitativo, bibliográfica e documental, como técnicas utiliza a entrevista semiestruturada, questionário, grupo focal e observação, apresenta resultados de pesquisa desenvolvida no programa de mestrado NAEA/UFPA 
da presa com baixa escolaridade e renda, desagregação da família, dificuldade de acesso à saúde pertencente ao universo prisional em grande parte estava presente fora dele no meio social. Os dados levantados corroborando com a tese de que o sistema penal é seletivo e escolhe a massa dos excluídos marcada pela pequena quantidade de capitais econômicos, culturais e sociais. E, mesmo considerando que o crime pode está presente em todas as classes sociais o apenamento com a privação da liberdade somente ocorreu a uma clientela selecionada.

A presa condenada no Pará tem o seguinte retrato com percentuais aproximados: $76 \%$ são paraenses, metade estão em regime fechado, com idade média de 34 anos, sendo que $60 \%$ têm no máximo 34 anos, $80 \%$ estão presas por tráfico, metade cumpriu entre um (1) a três (3) anos da pena, com média de condenação de oito (8) anos, tendo como concentração de ingresso o ano de 2011 , destaca-se que $70 \%$ não tem advogado, são mães com média de três filhos, e $67 \%$ deseja estudar e/ou trabalhar no futuro.

Ressalta-se que Marabá apresenta diferenças, pois quase metade é oriunda de outros estados, com maior percentual de condenaçóes por tráfico (90\%) do estado. Enquanto Santarém destaca-se pelo maior percentual do regime fechado com $71 \%$.

Constatou-se em relação ao capital social que $61 \%$ se declara pardas ou negras, $83 \%$ heterossexuais, $88 \%$ são mães, mais da metade dos filhos estão sob a guarda dos ascendentes, somente $10 \%$ estão com o pai, aproximadamente $45 \%$ não recebem visitas familiares sendo declarado como principal fator impeditivo a distancia para o CR, seguidas de razóes financeiras e do desejo de não recebe-las, metade dos parentes que exercem visita são mãe ou filho, e somente $20 \%$ é composta de marido/companheiro, a população e majoritariamente solteira com $58 \%$ aproximadamente, $2 / 3$ não recebem visitas intimas, mais da metade não recebe qualquer assistência da família, 48\% dos maridos ou companheiros respondem a processo criminal, $70 \%$ estão trabalhando não havendo distinção se dentro ou fora da prisão, um terço cometeu o delito com o marido ou companheiro. Em Santarém ocorrem especificidades apresentando um número significativo de bissexuais representando $1 / 4$ das presas e o maior percentual de visitas intimas com quase $65 \%$ e quase $90 \%$ dos maridos ou companheiros respondem a processo. No instrumento qualitativo detectou-se que as relaçóes familiares são pautadas por constrangimento no exercício da visita e ausência de espaço físico adequado como o berçário, as relaçôes com os funcionários apresentam-se conflituosas em decorrência do tratamento conferido as visitas, registrou-se denuncia de autoritarismo e subtração de objetos e alimentos.

No que tange o capital econômico quase metade declara exercer a profissão de empregada domestica, quase $70 \%$ exerceu trabalho infantil, menos de $10 \%$ tinham CTPS assinada antes da prisão, somente $20 \%$ auferiam renda superior a um salário mínimo, e quase $45 \%$ ganhava até meio salário mínimo, mais da metade trabalham na prisão, 
mais de 90\% percebem somente $\mathrm{R} \$ 99,00$ (noventa e nove reais). As mulheres presas em Marabá apresentavam o dobro de CTPS assinadas antes do cárcere. Destaca-se que em Santarém mais de 70\% de empregadas domésticas antes do cárcere, tais diferenças explica-se pelo desenvolvimento econômico regional. Os dados qualitativos apresentam sentimento dicotômico em relação ao trabalho, pois há valorização do trabalho realizado fora da prisão ou em funções profissionalizantes, e de outra banda sentimento de exploração com o trabalho exercido na prisão, que somente é realizado para remição da pena. O ingresso em concurso público é visto como alternativa extramuros e o prazo de cinco anos para presta-lo como injusto.

Detectou-se na pesquisa que mais de $65 \%$ das presas são analfabetas ou tem ensino médio incompleto; quase metade declara não estudar, a avaliação da qualidade de ensino com conceitos bom e excelente ultrapassa metade, $40 \%$ declaram que sempre leem na prisão, e quase $70 \%$ afirmam que nunca realizou qualquer atividade relacionada a esporte, teatro e dança, e 47\% afirmam que nunca assistiram filmes na prisão. Marabá apresenta a melhor qualidade de ensino com $65 \%$ de avaliação bom e excelente e Santarém apresenta a maior escolaridade do Pará com $65 \%$ das presas com ensino médio incompleto. Evidenciou-se com o grupo focal que a oferta de vagas escolares é insuficiente, a ausência de merenda e materiais escolares são fatores que dificultam o aprendizado, o estudo no cárcere foi apresentado como oportunidade negada no ambiente externo e requisito para a futuro emprego, ressurgindo a hostilização pelos funcionários e o uso de algema como fatores desmotivadores.

Diagnosticou-se que o acesso ao tratamento de saúde dificilíssimo e a qualidade precária, 46,5\% declaram padecerem de alguma doença, tendo como maiores percentuais hipertensão, seguido de gastrite e depois cisto ou mioma; $88 \%$ já precisou de atendimento médico, e $60 \%$ avaliam como péssimo, mais da metade nunca receberam o tratamento médico que necessitavam e somente $13 \%$ sempre foram atendidas. Ananindeua apresenta a maior necessidade de tratamento de saúde, pois 56\% das presas afirmam serem portadoras de doenças enquanto Marabá apresenta a melhor avaliação do serviço de saúde. Apresentou-se no grupo focal o sentimento de total abandono e omissão do Estado, a indiferença e normalidade da doença, a impossibilidade de oferecimento de tratamento como regra, a existência da "água milagrosa" expressão usada por presas e funcionários em decorrência da inexistência de medicamentos, o fortalecimento da fé em Deus pela ausência de tratamento.

Ao passo que em relação às drogas os dados quantitativos são dicotômicos, pois $80 \%$ declaram não usar drogas na prisão, todavia quando perguntado sobre a necessidade de tratamento $43 \%$ preferiu náo responder, sendo que 11 mulheres em Ananindeua declaram que gostariam de receber tratamento. Ao passo que nos dados levantados pela técnica qualitativa relata-se elevado índice de usuárias, surge à ideia do vicio adquirido no cárcere, 
do tratamento oferecido ser inadequado por realizar-se no hospital psiquiátrico, piorando o quadro, e da ocorrência de violência sexual durante o tratamento.

A discussão da criminalidade não pode prescindir da discussão de gênero do papel da mulher na sociedade, demonstrando-se pelo perfil da encarcerada que a mulher de classe média, inserida no mercado de trabalho formal, com maior capital econômico e cultural, frequentando as universidades e que tem acesso as novas tecnologias não estão inclusas no sistema penitenciário. Portanto, todo debate em torno do papel da mulher na sociedade, social, sexual ou no mundo do crime, deve ter como premissa a dominação social a exclusão social da mulher, e a quantidade de capitais detidos, tais condiçóes também se reproduz no mundo do crime e tem consequências no cárcere.

Infere-se que a população carcerária feminina condenada é jovem, de baixa escolaridade, recebia menos que um salário mínimo, estava inserida no mercado informal especialmente como doméstica, são mães com mais de três filhos, apresentam grau importante de ruptura com laços familiares ampliando a vulnerabilidade, tem história de envolvimento com drogas pelo uso ou pelo tráfico e exerceu trabalho infantil. Durante o cárcere quase metade declara não estudar, mais da metade trabalham na prisão, sendo que a renda auferida para $90 \%$ é menos que cem reais, necessitam de tratamento de saúde durante o cárcere, e mais da metade nunca recebeu o tratamento médico que precisava, e quando o recebem avaliam como de péssima qualidade, aproximadamente $45 \%$ não recebem visitas familiares, $2 / 3$ não recebem visitas intimas, mais da metade não recebe qualquer assistência da família, um terço cometeu o delito com o marido ou companheiro e quase metade dos maridos ou companheiros respondem a processo criminal.

Tais dados compóem um retrato de exclusão social a que esta população foi submetida antes do ingresso na prisão, aprofundando-se com o aprisionamento, em sua trajetória foram vitimizadas pela pobreza e pela desigualdade social. As conclusóes reforçam um ciclo no sistema penal baixo capital econômico, social e cultural - criminalidade - cumprimento da pena - liberdade - ampliação da vulnerabilidade - baixo capital econômico, social e cultural.

Constatou-se que em relação ao acesso a justiça 70\% são assistidas somente pela Defensoria Pública, pois não tem advogado particular. Dois terços dos defensores declaram que nunca ingressaram com qualquer ação para consecução de direito social, a Defensoria no período pesquisado não propôs qualquer ação judicial visando à ampliação de renda, educação ou saúde. Em relação ao capital social verificou-se que a Defensoria Pública ajuizou duas açóes individuais uma para garantir a visita intima homoafetiva, uma em Ananindeua e outra em Santarém, a primeira impulsionou a publicação de portaria regulamentando a visita homoafetiva em Ananindeua e a segunda possibilitou o exercício da visita para todas as demais em Santarém. 


\section{Conclusões}

A mulher encarcerada integra um grupo de relevante vulnerabilidade, tendo com muita facilidade seus direitos humanos violados, em especial os relativos à realização de direitos sociais, tais quais: o acesso à educação, seja formal ou informal; contato com a sociedade e possibilidade de reinserção social e no mercado de trabalho. Antes, durante e após o cárcere, essas mulheres têm baixo capital econômico, integrando a clientela preferencial do direito penal, qual seja, os pobres.

$\mathrm{O}$ conceito de vulnerabilidade e violação de direitos não pode ser cindido da compreensão de desenvolvimento, a partir da realização do ser humano, e da mulher de toda a sua potencialidade. Não se trata, por conseguinte, da ressocialização, e sim de ampliação de possibilidade de exercício de poder, das relaçóes desenvolvidas da mulher com o mundo.

Assim, amplia-se a leitura somente econômica da vulnerabilidade desvelando relaçôes de poder submersas no discurso legitimador do direito penal. Logo, apesar do atendimento das necessidades básicas, está destacado em vários documentos internacionais, em particular no que se refere à educação dos grupos vulneráveis e mais pobres, como precondição para o desenvolvimento sustentável e a estabilidade social e política, o que permite maior participação de segmentos populacionais, hoje praticamente alijados do processo político.

Está estabelecida nos documentos do PNUD a firme convicção de que o fortalecimento das instituiçóes nacionais e internacionais de proteção aos grupos vulneráveis é indispensável para a promoção da democracia, da realização dos direitos humanos e do desenvolvimento. E do relatório de 2010, é preciso trazer à baila o paradigma do desenvolvimento humano como fundamento ético à expansão das liberdades, entendidas como possibilidades de os indivíduos e as coletividades realizarem plenamente suas potencialidades.

Ainda estamos longe da inclusão e redução da vulnerabilidade, posto que isso requer não só ausência de obstáculos institucionais à tomada de decisóes e açóes (instituiçôes democráticas, direitos humanos), mas reais chances materiais, físicas e simbólicas para tomar decisões e executar ações que garantam acesso à ocupação produtiva, ao rendimento, aos estudos e a uma vida saudável.

No caso brasileiro, tem presença marcante nos organismos internacionais, uma diplomacia ativa que ratifica os tratados e os faz ingressar no ordenamento jurídico. E, além disso, é marcado pela heterogeneidade e pluralismo, que deve integrar tal ordenamento à agenda política, ao planejamento e execução de políticas públicas, ampliando as açóes afirmativas já em curso, e ampliando-as para a perspectiva dos integrantes do sistema penal, em especial do gênero feminino e as egressas, desafio que precisa ser pensado e vencido. 
Para tanto, é mister o fortalecimento das instituição nacionais e internacionais de proteção aos grupos vulneráveis, havendo a necessidade de articulação entre as instituiçôes públicas e as organizaçóes da sociedade civil e o empresariado para tal desiderato.

Há ainda um agravante em relação à mulher presa que precisa ser lembrado, qual seja, o estigma pelo cometimento do crime, a baixa renda, a falta de formação profissional para o mercado formal, a quase ausência de cursos para mercado formal, a ausência de financiamento para os empreendimentos, a falta de representaçáo política. Assim, este grupo torna-se como um dos últimos a ser alcançado por qualquer benefício social; pois quando efetivamente isto ocorre, não se tem condiçóes de participar ou influenciar no processo de tomada de decisão.

É necessário o desenvolvimento de novas estratégias de ação que perpassam por uma atuação política para construção da agenda para elaboração de políticas públicas com vista à aquisição de recursos que podem ser advindos de instituiçóes nacionais e internacionais. Além disso, a imprescindível participação da sociedade civil; a atuação jurídica mais efetiva por meio de ações coletivas ou ações civis públicas para a realização dos direitos, em especial, os sociais desse grupo vulnerável; a intensificação da produção acadêmica na área, para estudar os papéis a serem desempenhados pelas ONGs; a utilização da rede de assistência já criada para a criança e adolescente; o estabelecimento de parcerias entre entidades públicas e privadas. E, finalmente, o chamamento do setor privado para que, caso ingresse nos presídios, o faça de forma articulada com as políticas públicas, para que dessa forma possam contribuir positivamente para o desenvolvimento da mulher presa.

A atuação do Estado e a execução de políticas públicas ganham importância, em especial dos agentes jurídicos juízes, promotores, defensores e procuradores, haja vista porque podem buscar o rompimento com a lógica do campo social e ser essa parcela de profissionais envolvidos no campo jurídico que está buscando a ruptura das representaçóes.

Portanto, acredita-se que o caminho a ser trilhado pelo poder público reside na atuação administrativa, na elaboração, na execução e na avaliação de políticas públicas ou na judicialização de demandas visando à consecução de sua cidadania, com ampliação de suas possibilidades econômico, cultural e social para realização de seus direitos sociais e, por conseguinte, atingindo a redução da vulnerabilidade da mulher presa. Essa é sem dúvida a ideia norteadora.

E, visando o empowerment, traduzido comumente como empoderamento dos grupos vulneráveis, em uma tradução mais literal, no que se prefere à ampliação da capacidade de potencializar a atuação desses grupos, em conjunto com a esfera pública que poderá ser mais democrática e com a sociedade civil que atualmente tem a tendência de atuação em rede. 
Dentro das estratégias, destaca-se "o empowrment da sociedade civil organizada, que se mede pela sua capacidade de ter demandas e projetos reconhecidos e aceitos em suas negociações com os representantes do mercado e do Estado, nos conselhos e conferencias" (SCHERER-WARREN, 2006, p. 135). A gestáo de políticas públicas pode ser mais ou menos influenciada pela sociedade civil, no que dependerá das relaçóes de forças entre representantes das redes de movimentos sociais, da esfera estatal, do mercado de conselhos setoriais e das grandes conferências (SCHERER-WARREN, 2006).

Todavia, sem a participação da sociedade civil e o empowrment desses grupos que lhes permita pensar em suas demandas, estabelecer suas necessidades e ampliar a sua capacidade como sujeito, o desenvolvimento humano não ocorrerá.

Outro ponto que deve ser analisado é o fato de, apesar do avanço das discussốes das questôes de gênero, o cárcere ainda não ter entrado nessa agenda política de forma contundente, permanecendo a mulher caracterizada como grupo vulnerável, e tendo necessidade de especial atenção à saúde e educação. Entretanto, a questão carcerária ainda não foi construída: eis o desafio.

\section{Referências}

AGABEN, Giorgio. Homo sacer: o poder soberano e a vida nua.2. ed. Tradução de Henrique Burigo. Belo Horizonte:UFMG, 2010.

ARBEX Jr., José. Showrnalismo: a notícia como espetáculo. 4. ed. São Paulo: Casa Amarela, 2005.

AZERÊDO, Sandra. Preconceito contra a mulher: diferença poemas e corpos. 2. ed. São Paulo: Cortez, 2011.

BARCHIFONTAINE, Christian de Paul de. Vulnerabilidade e dignidade humana. O mundo social, São Paulo, ano 30 v. 30 n. 3 jul./set. 2006. Disponível em: <http:// www.scamilo.edu.br/pdf/mundo_saude/38/vulnerabilidade_dignidade.pdf>. Acesso em: 29 mar. 2012.

BATISTA, Nilo; ZAFFARONI, Eugenio Raúl; SLOKAR, Alejandro; ALAGIO, Alejandro. Direito Penal Brasileiro - I. 3. ed. Rio de Janeiro: Revan, nov. 2003-2006.

BEIRAS, Ińaki. La devaluaciòn de los derechos fundamentales de losreclusos. La construcción jurídica de um ciudadano de segunda categoria. Barcelona: Libreria Boch, 1997.

BONJARDIM, Estela Cristina. O acusado, sua imagem e a mídia. São Paulo: Max Limonad, 2002.

BOURDIEU, Pierre.. O poder simbólico. Tradução Fernando Tomaz (português de Portugal) 14. ed. Rio de Janeiro; Bertrand Brasil, 2010. 
BRASIL. Relatório do desenvolvimento humano de 2011. Sustentabilidade e equidade: um futuro melhor para todos. Disponível em: <http://www.pnud.org.br>. Acesso em: 05 jan. 2014.

. Relatório do desenvolvimento humano de 2013. Progresso humano num mundo diversificado: <http://www.pnud.org.br>. Acesso em: 05 jan. 2014.

. Projeto mulheres/DEPEN. Mulheres Presas: dados gerais. Disponível em:< www.mj.gov.br/depen>. Acesso em: 10 out. 2012.

Agenda 21. Disponível em: <http://www.mma.gov.br/responsabilidade-socioambiental/agenda-21/agenda-21-global>. Acesso em: 21 mar. 2012.

BRAUNSTEIN, Helio Roberto. Gênero e prisáo: o encarceramento das mulheres no sistema penitenciário brasileiro, 2007. Disponível em: <http://www5.usp.br/pesquisa/ acervos-online/>. Acesso em: 29 mar. 2012.

CANÇADO TRINDADE, Antônio Augusto. Grupos vulneráveis e desenvolvimento humano. In: . (Org.). A incorporaçáo das normas internacionais de proteçáo dos direitos humanos no direito brasileiro. São José, CR: IIDH, ACNUR, CIVC, CUE, 1996.

CARLÁS, Marta B; SMIRCICH, Linda. Do ponto de vista da Mulher: Abordagens feministas em estudos organizacionais. In:Handbook de estudos organizacionais. (Org.). da edição original Stewart R, CybtiaHardy, Walter R. Nord; Miguel Caldas, Roberto Fachin. Tânia Fischer, org. da edição brasileira. São Paulo: Atlas, 1999.

COIMBRA CMB. Práticas Psi e Tortura no Brasil. Grupo tortura nunca mais. 2001. Disponível em: < http://www.torturanuncamais-rj.org.br>. Acesso em : 3 abr. 2012.

CONCEIÇÃO. Antonio Carlos de Lima da. Teorias feministas: da "questão da mulher" ao enfoque de gênero. RBSE, v. 8, n 24, p. 738-757, dez. 2009. Disponível em: <http://www.cchla.ufpb.br/rbse/Conceicao_art.pdf>. Acesso em: 6 jan. 2013.

DOS SANTOS, Maria de Nazaré Silva Gouveia. A execução da pena privativa de liberdade: a realidade atual do sistema penitenciário do Pará. 2004. 176 f. Dissertação (Mestrado em Direito), Universidade Federal do Pará UFPA, Belém, 2004.

FERREIRA, Jairo. Mídia, jornalismo e sociedade: a herança normalizada de Bourdieu. Estudos em Jornalismo e Mídia, v. 2, n.1, 2005. Disponível em: <http://www. periodicos.ufsc.br>. Acesso em: 5 jan. 2014.

IDH/DESENVOLVIMENTOHUMANO. Disponível em: http://www.pnud.org.br/ IDH/ DesenvolvimentoHumano.aspx?indiceAccordion=0\&li=li_DH>. Acesso em: 5 jan. 2014.

GARLAND, David. A cultura do controle: crime e ordem social na sociedade contemporânea. Rio de Janeiro: Revan, 2008. Disponível em: http://www.comciencia.br/ comciencia/?section=8\&edicao=35\&tipo=entrevista. Acesso em: 5 jan. 2014. 
GOFFMAN, Erving. Manicômios, prisóes e conventos. Tradução de Dante Moreira Leite. São Paulo: Perspectiva, 2010.

GOMES, Luiz Flávio. Direito Penal do Inimigo (ou inimigo do direito penal). Disponível em: <http://www.revistajuridicaunicoc.com.br/midia/arquivos/ArquivoID_47.pdf>. Acesso em: 5 jan. 2014.

GUIMARAES, Cristian Fabiano; MENEGHEL, Stela Nazaré; OLIVEIRA, Carmem Solveira. Subjetividade e estratégias de resistências na prisão. Revista Ciência e profissáo, Universidade Vale dos Sinos, v. 26 n. 4, p. 632-645, 2006.

GUIMARÃES, Lytton. Grupos vulneráveis e desenvolvimento humano. In: TRINDA$\mathrm{DE}$, Antonio Augusto Cançado (Ed.). A incorporação das normas internacionais de proteção dos direitos humanos no direito brasileiro. San José, C.R: IIDH, ACNUR, CIVC, CUE, 1996.

JAKOBS, Gunter; MÉLIA Manuel Cancio. Direito penal do inimigo. Porto alegre: Livraria do Advogado, 2001.

LEMOS-CAPELLER, Wanda da. Violência e politicas criminais de ajustamento social. Fascículos de Ciências penais, , ano 3. v. 3. trimestral out./nov./dez. p. 39-56, 1990. Porto Alegre: Sergio Antonio Fabris Editor.

MANSUR, Luci Helena Baraldo. Solidáo-solitude: passagem feminista do Estado civil ao território da Alma. São Paulo: Editora da Universidade de São Paulo, 2011.

PRADO, DaneielNicory do; XIMENES, Rafson Saraiva. Redesenhando a execuçáo penal 2: por um discurso emancipatório democrático. Salvador: Faculdade Baiana de Direito, 2012.

PUCSP. Disponível em:<http:// www.pucsp.br/ ecopolitica/projetos_fluxos/doc_principais_ecopolitica/Agenda21\%20Brasil.pdf>. Acesso em: 10 fev. 2013.

SANTOS, Boaventura de Sousa. Poderá o direito ser emancipatório?.Revista Crítica de Ciências Sociais [Online], 65 | 2003, colocado online no dia 01 Agosto 2012, criado a 28 Maio 2015. URL : http://rccs.revues.org/1180; DOI : 10.4000/rccs. 1180

Santos, Daiane Lima dos. A atuaçáo da Defensoria Pública do Pará e a mulher encarcerada / Daiane Lima dos Santos; Orientador, Josep Pont Vidal.- 2013.

SCOTT, Joan Wallach. Gênero: uma categoria útil de análise histórica. Educação \& Realidade. Porto Alegre, v. 20, n. 2, jul./dez. p. 71-99, 1995.

SCHERER-WARREN, Ilse. Inclusão social e cidadania: A perspectiva das organizações, redes e movimentos. In: AMARAL JUNIOR, Aércio; BURITY, Joanildo de A.(Org.). Inclusão social, identidade e diferença: perspectivas pós-estruturalistas de análise social. São Paulo: Annablume, 2006. 
SÉGUIN, Elida. (Coord.). Direitos das minorias. Rio de Janeiro: Forense, 2001.

. Minorias e grupos vulneráveis: uma abordagem jurídica. Rio de Janeiro: Forense, 2002.

SPOSATO, Karyna Batista. Mulher e cárcere: uma perspectiva criminológica. In: REALE JUNIOR, Miguel. PASCHOAL, Janaína. Mulher e direito penal. Rio de Janeiro: Forense, 2007.

SETTON, Maria da Graça Jacintho. Um novo capital cultural: pré-disposiçóes e disposiçôes à cultura informal nos segmentos com baixa escolaridade. Educ. Soc., Campinas, v. 26, n. 90, abr. 2005 . Disponível em <http://www.scielo.br/scielo.php?scrip$\mathrm{t}=$ sci_arttext\&pid=S0101-73302005000100004\&lng=pt\&nrm=iso >. Acesso em: 17 set. 2012 .

SOUZA, Jessé. A construção social da subcidadania: para uma sociologia política da modernidade periférica. Belo Horizonte: Editora UFMG; Rio de Janeiro: IUPERJ, 2006. (coleção origem).

VIEIRA, Ana Lúcia Menezes. Processo penal e mídia. São Paulo: Revista dos Tribunais, 2003.

ZAFFARONI, Eugenio Raúl; SLOKAR, Alejandro; ALAGIO, Alejandro. Derecho Penal: Parte general. 2. ed. Buenos Aires: Ediar, 2002.

WACQUANT, Loic. Punir os pobres: a nova gestão da miséria nos Estados Unidos [A onda punitiva]. 3. ed. ver. amp. Tradução de Sergio Lamarão. Rio de Janeiro: Revan, 2003- 2007. 